\title{
Direct Assay of Enzymes in Heme Biosynthesis for the Detection of Porphyrias by Tandem Mass Spectrometry. Uroporphyrinogen Decarboxylase and Coproporphyrinogen III Oxidase
}

\author{
Yuesong Wang ${ }^{\dagger}$, Paula Gatti $^{\dagger}$, Martin Sadílek ${ }^{\dagger}$, C. Ronald Scott ${ }^{\ddagger}, \S$, František Tureèek ${ }^{*}, \dagger$, and \\ Michael H. Gelb ${ }^{*}, \dagger, \S$ \\ Departments of Chemistry, Pediatrics, and Biochemistry, University of Washington, Seattle, \\ Washington 98195-1700
}

\begin{abstract}
We report new assays of enzymes uroporphyrinogen decarboxylase (UROD) and coproporphyrinogen III oxidase (CPO) in the heme biosynthetic pathway. The assays were developed for use in clinical diagnostics of inherited disorders porphyria cutanea tarda and hereditary coproporphyria, respectively. Electrospray ionization tandem mass spectrometry is used to monitor the decarboxylation of pentaporphyrinogen I or uroporphyrinogen III catalyzed by UROD and to determine the enzyme activity in human erythrocytes by measuring the production of coproporphyrinogen I or III. The $K_{\mathrm{m}}$ value for pentaporphyrinogen I was measured as $0.17 \pm 0.03$ $\mu \mathrm{M}$. A mass spectrometric assay was also developed for the two-step decarboxylative oxidation of coproporphyrinogen III to protoporphyrinogen IX catalyzed by CPO in mitochondria from human lymphocytes $\left(K_{\mathrm{m}}=0.066 \pm 0.009 \mu \mathrm{M}\right)$. The assays show good reproducibility, use simple workup by liquid-liquid extraction of enzymatic products, and employ commercially available substrates and internal standards.
\end{abstract}

Porphyrias are a group of rare diseases caused by enzyme deficiencies in the heme biosynthetic pathway. ${ }^{1}$ Heme biosynthesis starts from succinyl-CoA and glycine and involves eight enzymatic steps, of which seven are connected with known enzyme deficiencies in humans.

${ }^{1}$ The enzyme uroporphyrinogen decarboxylase (UROD) catalyzes stepwise decarboxylation of heme precursor uroporphyrinogen III, which is converted to coproporphyrinogen III (Scheme 1). Lack of UROD is the basic cause of porphyria cutanea tarda (PCT), the late skin form of porphyria, with onset in adult life. PCT is the most common form of porphyria, which occurs in two clinical familial and a sporadic form. The familial forms of PCT are inherited as an autosomal dominant trait, in which UROD is reduced in all tissues. A severe form of PCT, hepatoerythropoietic porphyria (HEP), has its onset in infancy and is characterized by a very low level of UROD in red blood cells. The sporadic form is more common, and UROD activity is reduced in the liver only. Sporadic PCT is often associated with liver disease caused by alcoholism, hepatitis $\mathrm{C}$, or estrogen intake by women. The PCT manifests itself by blisters, which become ulcerated in areas of the skin exposed to sunlight, especially on the face, ears, and hands. The affected areas of skin tend to be fragile and show hyperpigmentation and hypertrichosis.

\footnotetext{
* To whom correspondence should be addressed. E-mail: turecek@ chem.washington.edu (F.T.), gelb@ chem.washington.edu (M.H.G.). $\dagger$ Department of Chemistry.

\$Department of Pediatrics.

$\S$ Department of Biochemistry.
} 
Coproporphyrinogen oxidase (CPO) is a mitochondrial enzyme that catalyzes decarboxylative oxidation of two carboxyethyl groups in coproporphyrinogen III to form vinyl groups in another heme intermediate, protoporphyrinogen IX (Scheme 1). Mutations in the gene encoding CPO (located on chromosome 3q11.2) result in hereditary coproporphyria (HCP), an autosomal dominant acute hepatic porphyria, which is characterized by acute attacks of neurological dysfunction often provoked by drugs, fasting, menstrual cycle, or infectious diseases. $^{2,3}$

Current methods for analyzing UROD and CPO deficiencies are indirect as they rely on the analysis of porphyrin metabolites in urine, feces, or erythrocytes. These approaches are often frustrating because of variability of excretion or loss during purification by chromatography. For many of the heme biosynthetic enzymes, direct enzyme assays are either not readily available for diagnosis or rely on a complex array of bioanalytical techniques ${ }^{4-12}$ that often require separation of products by liquid chromatography. ${ }^{4,6}$ Fluorimetric assays have been developed ${ }^{7}$ but because of poor sensitivity have given way to radiometric assays, ${ }^{8}$ which suffer from the lack of a commercially available source of substrate.

We have been developing tandem mass spectrometry assays of enzymes in clinically relevant human samples, such as dried blood spots and cell lysates, for the biochemical analysis of inborn errors of metabolism, most notably lysosomal storage diseases. ${ }^{13,14}$ The method utilizes a designed, often synthetic, substrate for the selected enzyme, which is added to a biological sample. After incubation, the amount of enzyme-generated product is quantified, along with a mass-differentiated internal standard, by selective detection with electrospray ionization tandem mass spectrometry (ESI-MS/MS). Tandem mass spectrometry offers the advantages of analytical sensitivity, selectivity, low background, and speed and is also ideally set up for multiplex analysis, whereby the products of several different enzymes may be quantified during a single infusion into the instrument. We envision using ESI-MS/MS to directly quantify all of the enzymes in the heme biosynthetic pathway for the molecular analysis of porphyrias. In this first study, we report direct enzyme assays for UROD and CPO using ESI-MS/MS.

\section{EXPERIMENTAL SECTION}

\section{Isolation of Erythrocytes and Lymphocytes}

Detailed procedures including all chemicals and laboratory materials are given as Supporting Information. All experiments with human samples were conducted in compliance with Institutional Review Board guidelines.

\section{Materials and Methods}

Pentacarboxylporphyrin I dihydrochloride (Frontier Scientific, Inc., cat. no. P769-ID) was dissolved in $0.01 \mathrm{M} \mathrm{KOH}$, and the concentration was determined spectrophotometrically at $403 \mathrm{~nm}$ using an extinction coefficient of $\varepsilon=478000 \mathrm{M}^{-1} \mathrm{~cm}^{-1}$. This solution can be stored at $4{ }^{\circ} \mathrm{C}$ in a light-tight box for up to 1 month. Pentaporphyrinogen I was prepared ${ }^{4}$ by adding $200 \mu \mathrm{L}$ of porphyrin solution (typically $200 \mu \mathrm{M}$ ) to a vial with a Teflon septum-lined screw cap. Sodium amalgam (Sigma-Aldrich, cat. no. 451894-10G) (4-6 particles) was added, and the vial was wrapped with foil to exclude light. The cap was loosened, a needle from the $\mathrm{N}_{2}$ source was inserted through the septum into the airspace above the solution, and $\mathrm{N}_{2}$ was allowed to flow for $\sim 20 \mathrm{~s}$ before the cap was tightened and the needle removed. The solution was placed on a vortex mixer for $\sim 5$ min until the solution became colorless (foil removed temporarily). Two times during this mixing period, the vial was purged with $\mathrm{N}_{2}$ as above. The liquid was removed from the $\mathrm{Na}$ amalgam and diluted with distilled water to give $50 \mu \mathrm{M}$ 
pentaporphyrinogen I in a vial. After purging with $\mathrm{N}_{2}$ as above, the porphyrinogen solution was stored at $-80^{\circ} \mathrm{C}$. The solution was stable for up to 1 month.

\section{UROD Assay}

A literature method was adapted after Jones et al. ${ }^{4}$ UROD assay buffer $(125 \mu \mathrm{L}$ of $200 \mathrm{mM}$ potassium phosphate, $2.0 \mathrm{mM}$ EDTA, $10 \mathrm{mM}$ DTT, pH 6.8) was added to a $2.0 \mathrm{~mL}$ polypropylene microfuge tube followed by $50 \mu \mathrm{L}$ of diluted red blood cell lysates (Supporting Information), $20 \mu \mathrm{L}$ of pentaporphyrinogen I $(50 \mu \mathrm{M})$, and $55 \mu \mathrm{L}$ of distilled water. The tube was capped and incubated in a water bath at $37^{\circ} \mathrm{C}$ for $30 \mathrm{~min}$. The water bath chamber was covered with foil to exclude light. Acetic acid/ethyl acetate $(1.5 \mathrm{~mL} ; 3: 7, \mathrm{v} / \mathrm{v})$ was added to quench the reaction. Mesoporphyrin IX dihydrochloride (15.0 pmol, $15 \mu \mathrm{L}$ of $1 \mu \mathrm{M}$ in $1 \mathrm{M}$ $\mathrm{HCl}$, Frontier Scientific, Inc., cat. no. M566-9) was added as internal standard. The mixture was placed on a vortex mixer for $30 \mathrm{~s}$ before being centrifuged at $12000 \mathrm{~g}$ for $3 \mathrm{~min}$. The top $650 \mu \mathrm{L}$ of supernatant was transferred using a pipettor with a polypropylene tip to a new 1.5 $\mathrm{mL}$ polypropylene microfuge tube containing $650 \mu \mathrm{L}$ of sodium acetate $(3 \% \mathrm{w} / \mathrm{v})$. The mixture was placed on a vortex mixer for $30 \mathrm{~s}$ and centrifuged for $3 \mathrm{~min}$. The top $200 \mu \mathrm{L}$ ethyl acetate layer was transferred to another microfuge tube containing $200 \mu \mathrm{L}$ of distilled water, and the sample was placed on a vortex mixer for $30 \mathrm{~s}$ and centrifuged for $3 \mathrm{~min}$. The top $100 \mu \mathrm{L}$ of ethyl acetate was transferred to a new tube and dried under a $\mathrm{N}_{2}$ stream $(\sim 15 \mathrm{~min})$. The residue can be stored at $-20{ }^{\circ} \mathrm{C}$ until dissolved in $50 \mu \mathrm{L}$ of methanol with $1 \%$ formic acid immediately before ESI-MS/MS analysis.

\section{CPO Assay}

A stock solution of coproporphyrin III (Frontier Scientific, Inc., cat. no. C654-3) in $0.01 \mathrm{M}$ $\mathrm{KOH}$ was prepared and stored as above (extinction coefficient: $\varepsilon=478000 \mathrm{M}^{-1} \mathrm{~cm}^{-1}$ at 401 $\mathrm{nm}$ ), and this was converted with $\mathrm{Na}$ amalgam to coproporphyrinogen III as above. For CPO assays, $100 \mu \mathrm{L}$ of assay buffer ( $250 \mathrm{mM}$ Tris- $\mathrm{HCl}, 2.5 \mathrm{mM}$ EDTA, $\mathrm{pH} 7.15)$ was placed in a microfuge tube along with $50 \mu \mathrm{L}$ of diluted lymphocyte lysate (Supporting Information) and $80 \mu \mathrm{L}$ of distilled water. The reaction was started by adding $20 \mu \mathrm{L}$ of coproporphyrinogen III $(50 \mu \mathrm{M})$, and the solution was incubated in a water bath at $37^{\circ} \mathrm{C}$ for $60 \mathrm{~min}$ in the dark. The sample was processed for ESI-MS/MS as for UROD.

\section{Mass Spectrometry}

ESI-MS/MS for UROD was performed on a Waters Acquity TQD tandem quadrupole instrument operating in positive ion mode. Ion scanning was carried out with Masslynx software with the following settings: capillary voltage, $3.75 \mathrm{kV}$; cone voltage, $100 \mathrm{~V}$; extractor, $3 \mathrm{~V}$; rf, 0; source temperature, $80^{\circ} \mathrm{C}$; desolvation gas, $500 \mathrm{~L} / \mathrm{h}$; desolvation temperature, 350 ${ }^{\circ} \mathrm{C}$; dwell time, $100 \mathrm{~ms}$; collision gas, $0.21 \mathrm{~L} / \mathrm{h}$; collision energy, $45 \mathrm{eV}$.

ESI-MS/MS for CPO was performed on an Applied Biosystems API-4000 tandem quadrupole instrument operating in positive ion mode. Ion scanning was carried out with the Analyst software with the following settings: ion spray voltage, $3.5 \mathrm{kV}$; rf, 0; dwell time, $100 \mathrm{~ms}$; collision gas, 4; collision energy, $45 \mathrm{eV}$.

\section{RESULTS AND DISCUSSION \\ Uroporphyrinogen Decarboxylase}

The enzyme-catalyzed formation of uroporphyrinogen III (1) is accompanied by nonenzymatic formation of an isomer, uroporphyrinogen I (2), which has a rotated D ring (Scheme 2). Uroporphyrinogen I is also recognized as substrate by UROD and is decarboxylated to coproporphyrinogen I (8), an isomer of coproporphyrinogen III (6). This feature can be utilized 
to develop assays of UROD using either the uroporphyrinogen I or III decarboxylation pathways. The porphyrinogen intermediates 3-6 and $\mathbf{7}$ undergo spontaneous oxidation to the corresponding porphyrins (3P-6P and 7P) upon exposure to air and light, ${ }^{15}$ as shown for $\mathbf{6}$ in Figure 1. However, Figure S1 (Supporting Information) shows less than $10 \%$ decrease of the enzymatic product formation from uroporphyrinogen III when the assays were performed in the presence of atmospheric oxygen and excluding light. Thus, nitrogen protection was not deemed to be necessary and was not used in the UROD assays. Conversely, the spontaneous oxidation of the porphyrinogens was utilized for analysis, as the resulting porphyrins are both stable in solution and readily ionized by ESI to form protonated ions. These are generically denoted as $(\mathrm{M}+\mathrm{H})^{+}$in the text. The time course of spontaneous oxidation was studied for $\mathbf{1}$, which was found to be completely converted to uroporphyrin upon workup in less than $20 \mathrm{~min}$ (Figure S2, Supporting Information).

The MS/MS assays of UROD were based on the loss of a $\mathrm{CH}_{2}-\mathrm{COOH}$ (59 Da) neutral fragment from protonated porphyrins, which represented a major primary dissociation upon collisional activation at $45 \mathrm{eV}$. This dissociation forms stable conjugated methylenepyrrole cation-radicals as products, as shown for coproporphyrin I (8P, Figure 1). The collision-induced dissociation (CID) mass spectra of $(\mathrm{M}+\mathrm{H})^{+}$ions further showed consecutive losses of substituents $\left(\mathrm{CH}_{3}, \mathrm{COOH}, \mathrm{CH}_{2} \mathrm{COOH}\right.$, and $\left.\mathrm{CH}_{2} \mathrm{CH}_{2}-\mathrm{COOH}\right)$ from the porphyrin ring whose mechanisms were not studied in detail. Mesoporphyrin IX (9P) was used as an internal standard for quantitation using the loss of a 59 Da neutral fragment in MS/MS. The molecular masses and ion $\mathrm{m} / \mathrm{z}$ values for all pertinent analytes are given in Table 1. We note that although the other abundant fragment ions in the CID mass spectra could also be used to monitor the porphyrins, the common loss of $59 \mathrm{Da}$ fragment gives the option of using neutral loss scan in the multiple reaction monitoring scheme.

The responses in ESI-MS/MS of $\mathbf{3 P}-\mathbf{6 P}$ relative to that of $\mathbf{9 P}$ were determined to be 0.056 , $0.075,0.106$, and 0.301 , respectively, with a $3.5 \%$ coefficient of variation. The calibration curves for the MS/MS peak areas versus concentration, both relative to those of $\mathbf{9 P}$, showed good linearity, $r^{2} \geq 0.99, n=4$.

Using uroporphyrinogen III (1) as substrate, we monitored the formation of the stepwise decarboxylation products, hepta (3), hexa (4), penta (5), and coproporphyrinogen III (6) through ESI-MS/MS of the corresponding porphyrins (3P-6P, respectively). After $30 \mathrm{~min}$ of incubation, the reaction mixture contained mainly $\mathbf{3}$ (70\% of products) (Figure 2 ). The activity of UROD, measured for the formation of 3-6, showed a linear dependence on the amount of erythrocytes $\left(r^{2}=0.99, n=3\right)$ and substrate 1 for each product (Figure S3, Supporting Information). However, due to the consecutive reaction kinetics, the time-dependence curves of the 3-6 concentrations were nonlinear, and the formation of $\mathbf{6}$ showed a time lag (Figure S4, Supporting Information). The different time-dependence curves for 3-6 can be averaged out by combining the measured concentrations at any chosen time, as shown in Figure 2. The combined production of 3-6 showed good reproducibility ( $\pm 3 \%, 1 \mathrm{SD})$ in triplicate measurements of blood samples from four healthy individuals. A drawback of this assay is the necessity of monitoring MS/MS spectra for four ion dissociations plus that for the internal standard, which increases complexity and reduces the duty cycle of the measurements.

To avoid the time-dependence issues, an improved assay was developed that utilized the commercially available pentaporphyrinogen I (7) as a substrate, which undergoes URODcatalyzed decarboxylation to coproporphyrinogen I (8) in a single step. The mass spectrometric behavior of the corresponding coproporphyrin $(\mathbf{8 P})$ was found to be very similar to that of 6P in both protonation by ESI and CID. The formation of $\mathbf{8}$ from $\mathbf{7}$ showed a linear dependence on the incubation time in the interval of 5-60 min (Figure S5, Supporting Information) and also on the amount of the red blood cell lysate. The latter was quantified by measuring the 
hemoglobin content (Figure S6, Supporting Information). It is desirable to perform the assays at low conversions and thus to measure the initial enzyme velocity in order to avoid product binding and enzyme inhibition. Therefore, the UROD assay time was set at $30 \mathrm{~min}$, which was well within the linear portion of the time-dependence curve and resulted in the formation of $35 \pm 3$ pmol of $\mathbf{8}$ product per assay, corresponding to $3.5 \%$ substrate $\mathbf{7}$ conversion.

The average value for the standard UROD assay was $1.24 \pm 0.15 \mathrm{pmol} /(\mathrm{min} \cdot \mathrm{mg}$ of hemoglobin) of coproporphyrin for blood samples from four individuals. The Lineweaver-Burk plot of reciprocal UROD velocity over reciprocal concentration of 7 showed acceptable linearity $\left(r^{2}\right.$ $=0.97$, Figure S7, Supporting Information) and gave $K_{\mathrm{m}}=0.17 \pm 0.03 \mu \mathrm{M}$ for 7 . Due to the relatively rare incidence of hereditary porphyrias, no samples were available at this time to measure enzyme velocities in patients with confirmed PCT.

Oxidation of porphyrinogens has been reported to be complete in a few minutes of exposure to air and light after the enzymatic reaction was quenched by acid. ${ }^{15} \mathrm{We}$ tested both the conversion of coproporphyrinogen III to coproporphyrin III in the UROD assay and the recovery yields for $6 \mathrm{P}, \mathbf{8 P}$, and $9 \mathrm{P}$ by comparing the ratio of the corresponding ESI-MS peaks $(\mathrm{m} / \mathrm{z} 655$ and 567) in the extracts and after spiking with known amounts of $\mathbf{6 P}, \mathbf{8 P}$, and $\mathbf{9 P}$.

16 Briefly, coproporphyrinogen III was added to a blank UROD assay (no erythrocytes), followed by a standard workup after $30 \mathrm{~min}$. ESI-MS showed the peak of $(\mathrm{M}+\mathrm{H})^{+}$from $\mathbf{6 P}$ at $\mathrm{m} / \mathrm{z} 655$, while ions at $\mathrm{m} / \mathrm{z} 661$ corresponding to coproporphyrinogen 6 were weak, $[\mathrm{m} / \mathrm{z}$ $661] /[\mathrm{m} / z$ 655] $<0.05$. The ESI-MS measurements indicated that the oxidation was complete during the sample workup. The ESI-MS/MS analysis gave 94\% recovery for $\mathbf{6 P}$.

\section{Coproporphyrinogen Oxidase}

CPO converts coproporphyrinogen III (6) to protoporphyrinogen IX (11) through harderoporphyrinogen IX (10) (Scheme 3). CPO requires the presence of oxygen to convert 6 to 11 , and the mechanism of the enzyme action has been studied recently. ${ }^{17}$ In our approach, the enzyme was assayed with $\mathbf{6}$, and the formation of $\mathbf{1 1}$ was monitored by ESI-MS/MS after spontaneous oxidation to protoporphyrin 11P that occurred upon incubation and workup. The CID mass spectra of 11P and internal standard 9P are shown in Figure 3. $(\mathrm{M}+\mathrm{H})^{+}$ions from both porphyrins underwent a loss of a $\mathrm{CH}_{2} \mathrm{COOH}$ radical to give the diagnostic product ions at $\mathrm{m} / z 508$ and 504 for 9P and 11P, respectively. The other dissociations upon CID were analogous to those shown for $\mathbf{8 P}$ (Figure 1). The transitions $\mathrm{m} / \mathrm{z} 567 \rightarrow \mathrm{m} / \mathrm{z} 508$ and $\mathrm{m} / \mathrm{z} 563$ $\rightarrow m / z 504$ were used in multiple reaction monitoring of $\mathbf{9 P}$ and 11P, respectively. The response upon ESI-MS/MS of 11P relative to that of $\mathbf{9 P}$ was $I(\mathrm{~m} / \mathrm{z}$ 504 $) / I(\mathrm{~m} / \mathrm{z} 508)=0.352[c(\mathbf{1 1 P}) / \mathrm{c}$ (9P)], where $I$ and $c$ are the pertinent ion currents and concentrations, respectively. Thus, mesoporphyrin had the highest ESI-MS/MS response.

The coefficient of variation ion these measurements was 3\% $(n=5)$. Blank experiments were carried out in the absence of either lymphocytes or $\mathbf{6}$, which showed no detectable formation of 11. In the absence of oxygen, the formation of $\mathbf{1 1}$ was suppressed to ca. $2.5 \%$ of normal activity (Figure 4), in line with the known oxygen dependency of CPO. ${ }^{17}$ Under aerobic conditions, the average value for the standard assay was $10.1 \pm 1.3 \mathrm{pmol} /(\mathrm{min} \cdot \mathrm{mg}$ of lymphocyte protein) of 11P as measured in lymphocytes from five healthy individuals. The CPO activity was linear with respect to the amount of lymphocytes (Figure S8, Supporting Information). The Lineweaver-Burk plot of reciprocal CPO velocity over reciprocal concentration of 6 was linear $\left(r^{2}=0.974\right.$, Figure S9, Supporting Information) and gave $K_{\mathrm{m}}=$ $0.066 \pm 0.009 \mu \mathrm{M}$. ESI-MS/MS analysis showed that the recovery yield for 11P was $99 \%$. 


\section{CONCLUSIONS}

Tandem mass spectrometry provides a common instrument platform to assay UROD and CPO in biochemical and clinical analysis of PCT and coproporphyria, respectively. Due to the different molecular masses of the enzyme products, the assays can be readily multiplexed for a single injection into the mass spectrometer, if so desired to shorten the time of analysis. Each assay is performed on a microscale and consumes less than $1 \mathrm{nmol}$ of inexpensive substrates. In contrast to fluorimetric and radiometric assays, no chromatographic separation of substrates and products is necessary. As tandem quadrupole mass spectrometers are becoming standard equipment in clinical laboratories, new assays using ESI-MS/MS may represent a useful and attractive alternative to previous methods.

\section{Supplementary Material}

Refer to Web version on PubMed Central for supplementary material.

\section{Acknowledgements}

This work was supported by a Grant from the NDDK-National Institutes of Health (DK67869).

\section{References}

1. Kappas, A.; Sassa, S.; Galbraith, RA.; Nordmann, Y. The Porphyrias. In: Scriver, CR.; Beaudet, AL.; Sly, WS.; Valle, D., editors. The Metabolic and Molecular Basis of Inherited Disease. 7. II. McGrawHill; New York: 1995. p. 2103-2159.

2. Brodie MJ, Thompson GG, Moore MR, Beattie AD, Goldberg A. Quant J Med 1977;46:229-241.

3. Kuhnel A, Gross U, Doss MO. Clin Biochem 2000;33:465-473. [PubMed: 11074238]

4. Jones MA, Thientanavanich P, Anderson MD, Lash TD. J Biochem Biophys Methods 2003;55:241249. [PubMed: 12706908]

5. Francis JE, Smith AG. Anal Biochem 1984;138:404-410. [PubMed: 6742418]

6. McManus J, Blake D, Ratnaike S. Clin Chem 1988;34:2355-2357. [PubMed: 3180434]

7. Labbe P, Camadro JM, Chambon H. Anal Biochem 1985;149:248-260. [PubMed: 3907404]

8. Elder GH, Evans JO. Biochem J 1978;169:205-214. [PubMed: 629746]

9. Kardish RM, Woods JS. J Appl Biochem 1980;2:159-67.

10. Li F, Lim CK, Peters TJ. Biochem J 1986;239:481-484. [PubMed: 3814086]

11. Grandchamp B, Nordmann Y, Elder GH, Smith SG. Enzyme 1982;28:196-205. [PubMed: 7140721]

12. Gross U, Gerlach R, Kuehnel A, Seifert V, Doss MO. J Inherited Metab Dis 2003;26:565-570. [PubMed: 14605502]

13. Turecek, F.; Scott, CR.; Gelb, MH. Tandem Mass Spectrometry in the Detection of Inborn Errors of Metabolism for Newborn Screening. In: Secchi, S., editor. Quantitative Proteomics by Mass Spectrometry. Methods in Molecular Biology. 359. Humana Press; 2007. p. 143-158.

14. Gelb MH, Turecek F, Scott CR, Chamoles NA. J Inherited Metab Dis 2006;29:397-404. [PubMed: 16763908]

15. Erlandsen EJ, Jørgensen PE, Markussen S, Brock A. Scand J Clin Lab Invest 2000;60:627-634. [PubMed: 11202055]

16. Matuszewski BK, Constanzer ML, Chavez-Eng CM. Anal Chem 2003;75:3019-3030. [PubMed: 12964746]

17. Lee DS, Flachsova E, Bodnarova M, Demeler B, Martasek P, Raman CS. Proc Natl Acad Sci USA 2005;102:13232-14237. 


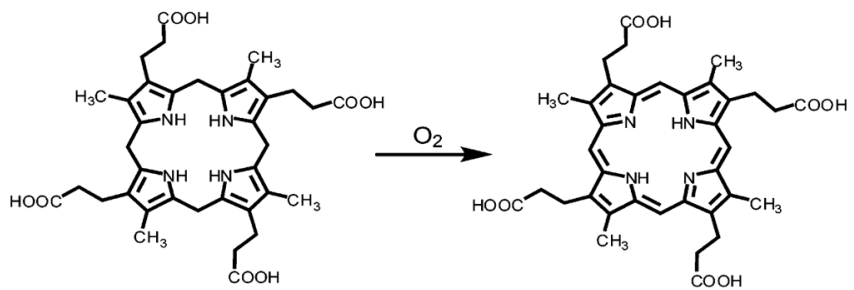

Coproporphyrinogen III

Coproporphyrin III

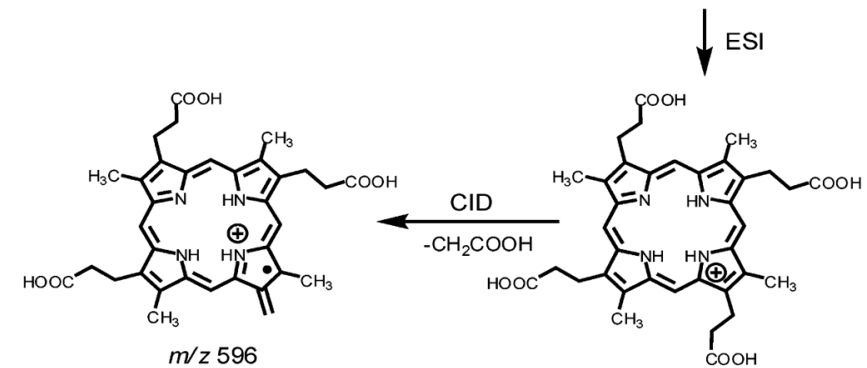

$(\mathrm{M}+\mathrm{H})^{+} \mathrm{m} / \mathrm{z} 655$

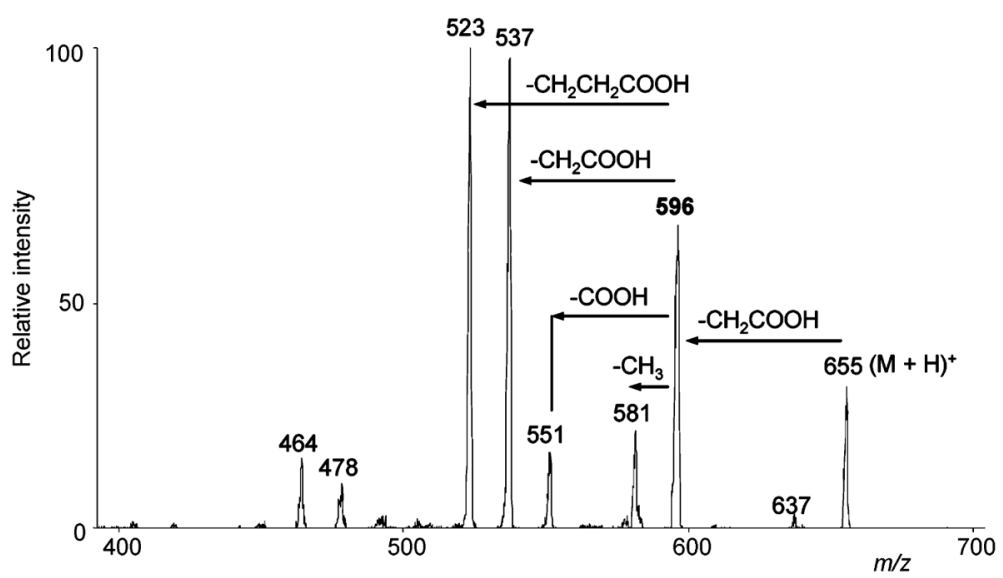

Figure 1.

Electrospray MS/MS spectrum of the $(\mathrm{M}+\mathrm{H})^{+}$ion at $m / z 655$ from coproporphyrin $\mathrm{I}(\mathbf{8 P})$. 


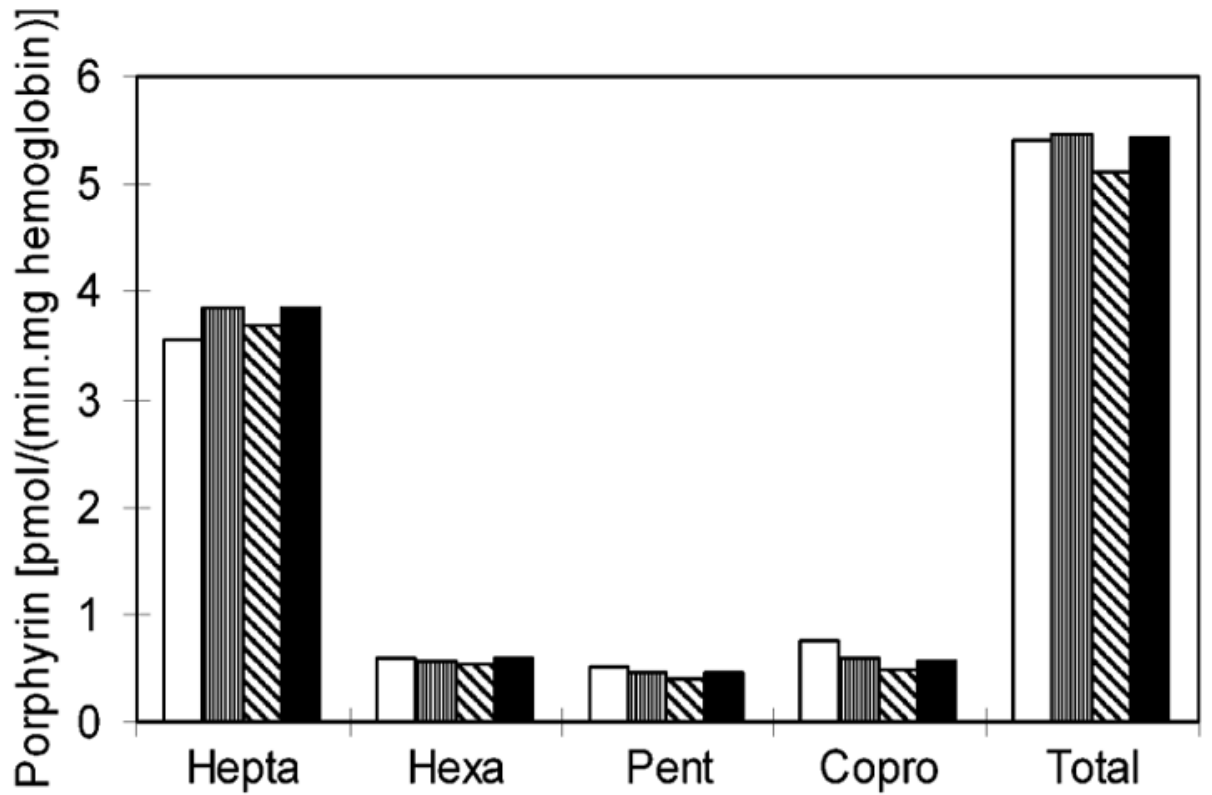

Figure 2.

UROD activities in the formation of $\mathbf{3}$ (hepta), $\mathbf{4}$ (hexa), $\mathbf{5}$ (penta), and $\mathbf{6}$ (copro) measured in blood samples from four individuals. The bars are means of triplicate measurements for each patient and porphyrinogen intermediate. 

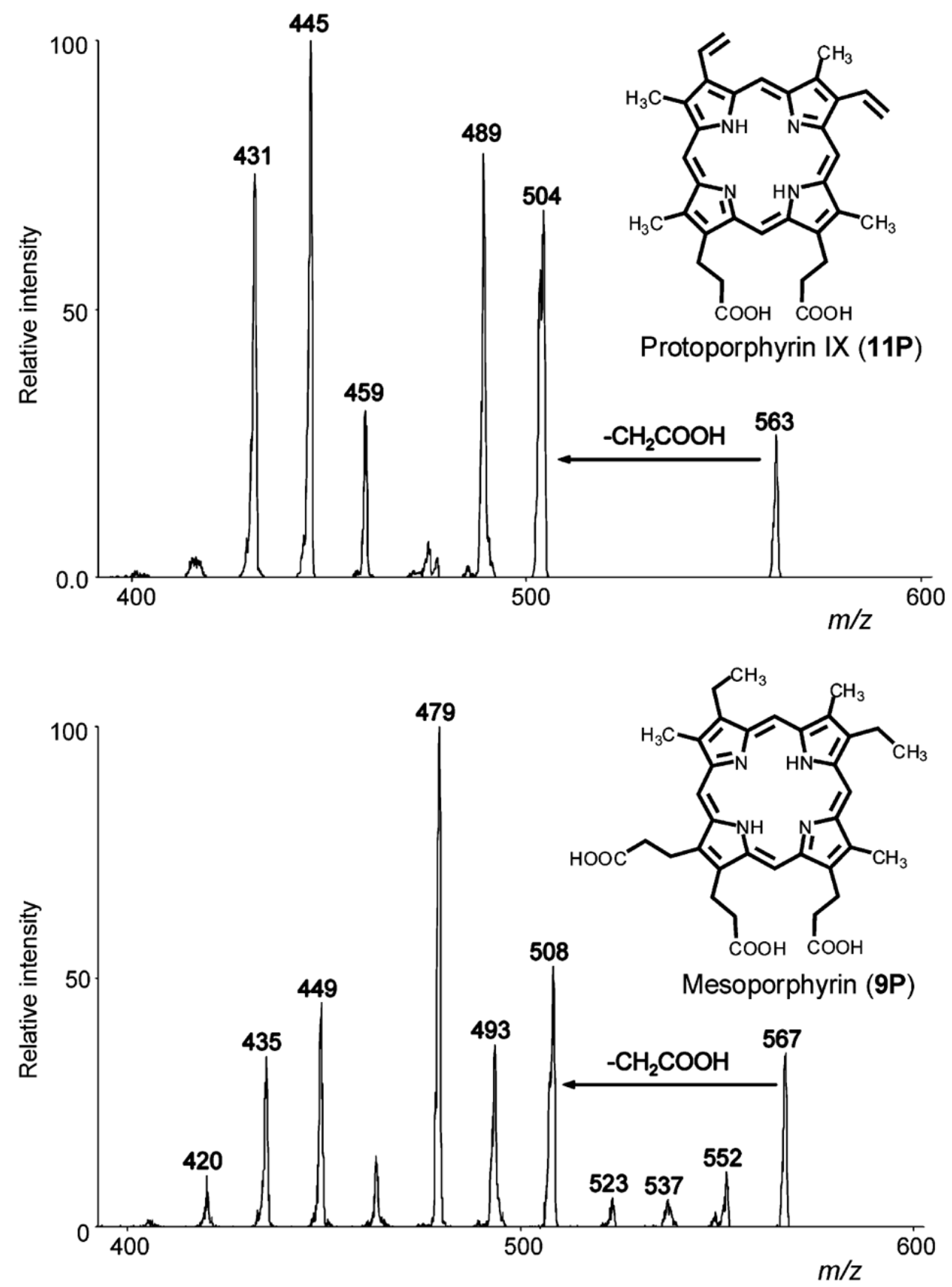

Figure 3.

Electrospray MS/MS spectra of (top) the $(\mathrm{M}+\mathrm{H})^{+}$ion at $m / z 563$ from protoporphyrin IX (11P) and (bottom) the $(\mathrm{M}+\mathrm{H})^{+}$ion at $\mathrm{m} / z 567$ from mesoporphyrin (9P). 


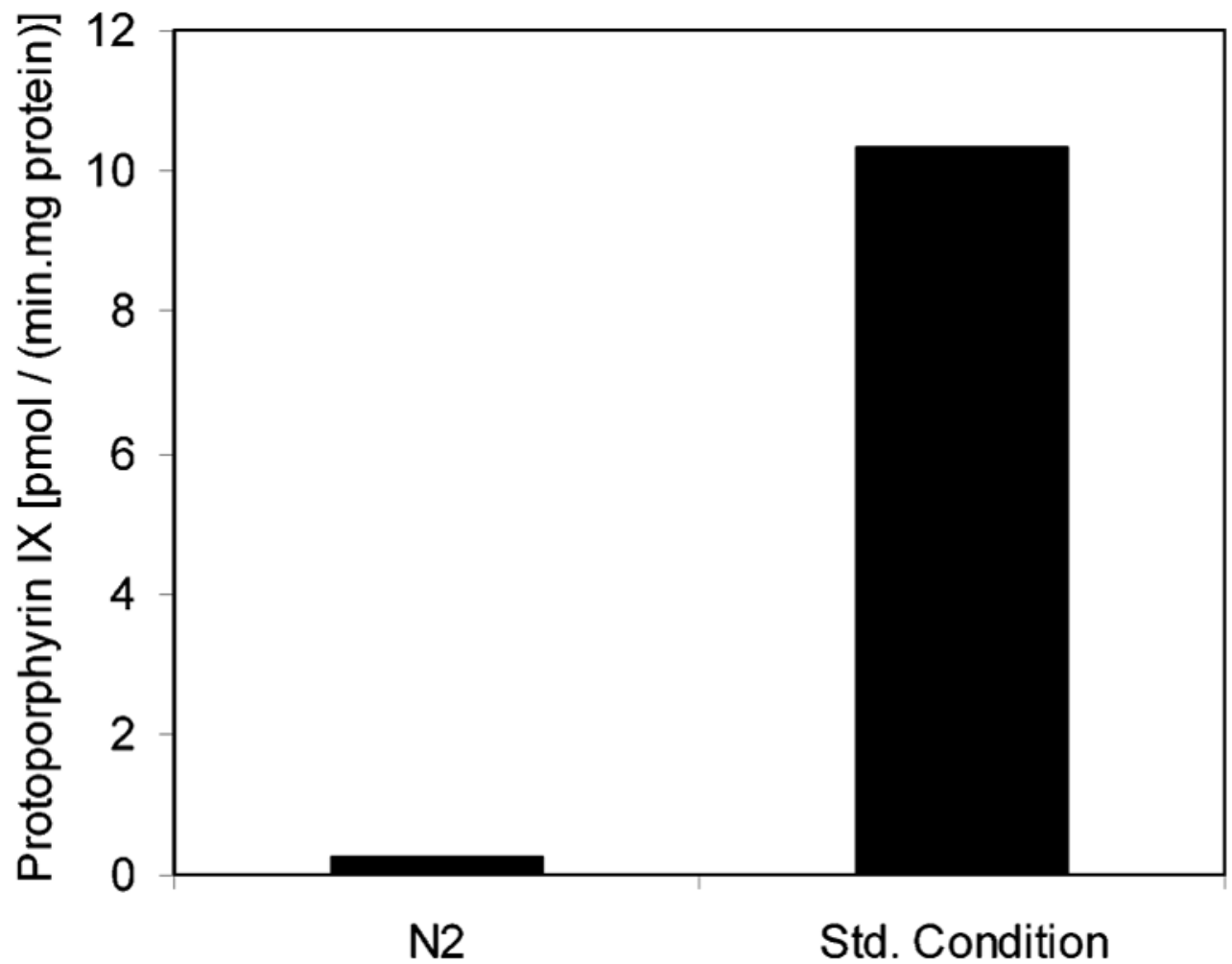

Figure 4.

CPO activity measured under $\mathrm{N}_{2}$ (left bar) and under aerobic conditions (right bar). Both assays were carried out at $37{ }^{\circ} \mathrm{C}$ using $4 \mu \mathrm{M}$ coproporphyrinogen III as substrate. 


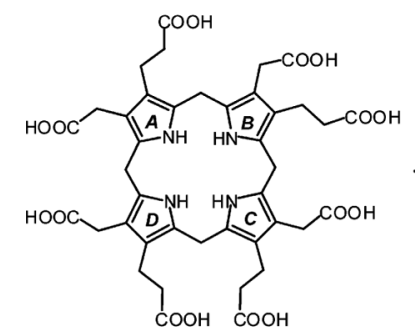

Uroporphyrinogen III
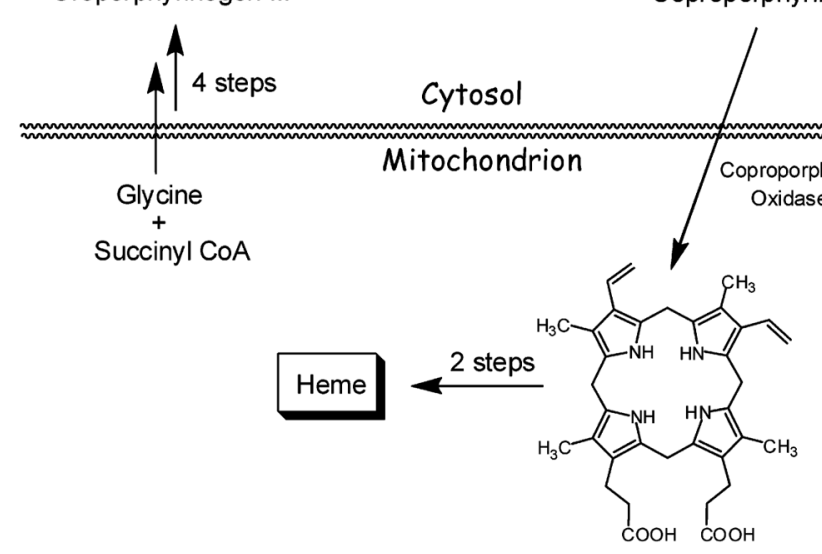

Protoporphyrinogen IX

Scheme 1. 


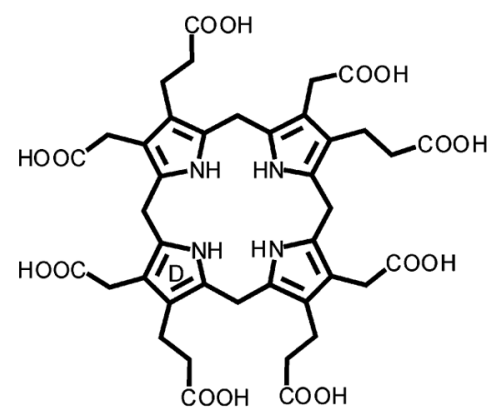

Uroporphyrinogen III (1)

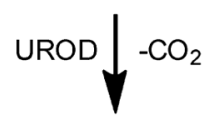

Heptaporphyrinogen III (3)

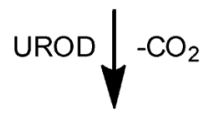

Hexaporphyrinogen III (4)<smiles></smiles>

Pentaporphyrinogen III (5)<smiles></smiles><smiles></smiles>

Coproporphyrinogen III (6)

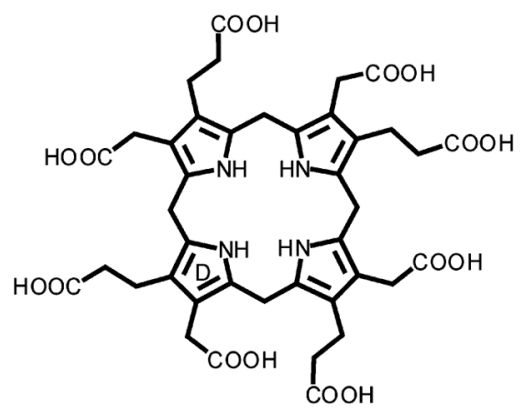

Uroporphyrinogen I (2)
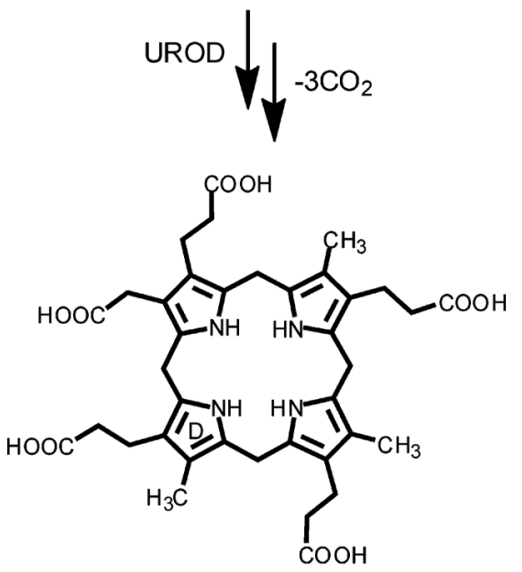

Pentaporphyrinogen I (7)
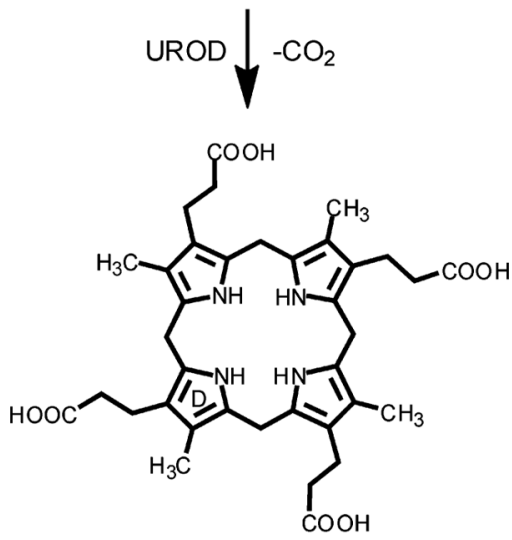

Coproporphyrinogen I (8)

Scheme 2. 

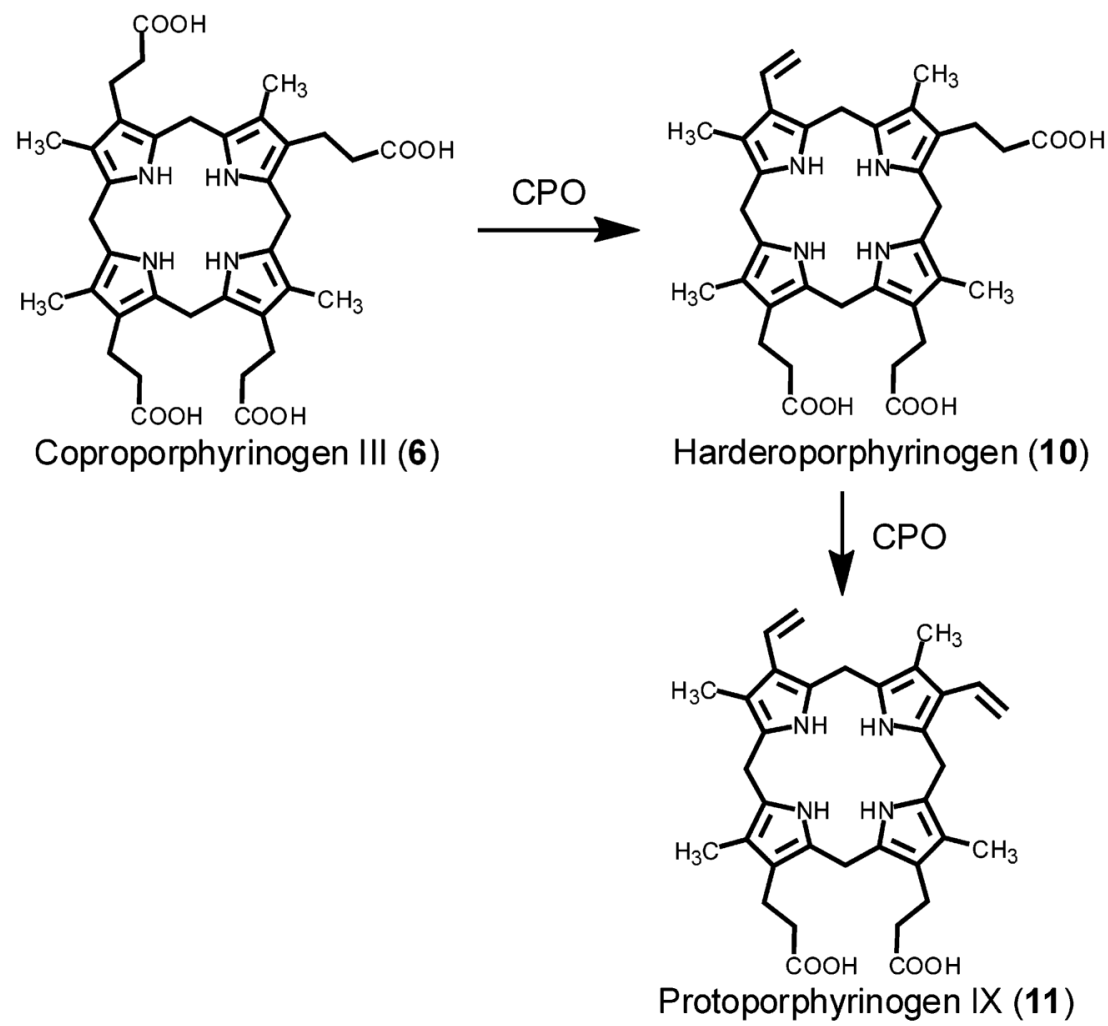

Scheme 3. 
Table 1

Mass Spectrometric Properties of Substrates and Products

\begin{tabular}{llcc}
\hline & & & \multicolumn{2}{c}{$\boldsymbol{m / z}$} \\
\cline { 3 - 4 } porphyrinogen & porphyrin (MW) & precursor $(\mathbf{M}+\mathbf{H})^{+}$ & reporter product ion \\
\hline $\mathbf{1 , 2}$ & $\mathbf{1 P}, \mathbf{2 P}(830.2)$ & 831.2 & 772.2 \\
$\mathbf{3}$ & $\mathbf{3 P}(786.2)$ & 787.2 & 728.2 \\
$\mathbf{4}$ & $\mathbf{4 P}(742.2)$ & 743.2 & 684.2 \\
$\mathbf{5 , 7}$ & $\mathbf{5 P}, \mathbf{7 P}(698.2)$ & 699.2 & 540.2 \\
$\mathbf{6 , 8}$ & $\mathbf{6 P}, \mathbf{8 P}(654.2)$ & 555.2 & 508.2 \\
$\mathbf{9}$ & $\mathbf{9 P}(566.2)$ & 609.2 & 550.2 \\
$\mathbf{1 0}$ & $\mathbf{1 0 P}(608.2)$ & 563.2 & 504.2 \\
$\mathbf{1 1}$ & $\mathbf{1 1 P}(562.2)$ & & \\
\hline
\end{tabular}

